\title{
The Periodic Table Possible Coincided with an Unfolded Shape of Atomic Nuclei
}

\author{
Jianping $\mathrm{Mao}^{1}$ \\ 1 201-A-22 Qinye Changzhou, Jiangsu 213016, China \\ Correspondence: Jianping Mao. E-mail:mjp00951@163.com
}

Received: October 11, 2017

Accepted: October 26, $2017 \quad$ Online Published: November 10, 2017

doi:10.5539/apr.v9n6p47

URL: https://doi.org/10.5539/apr.v9n6p47

\begin{abstract}
The periodic table seems to correspond to folding nuclei, a visible proton (nucleon) distribution, that can grow vertical $4 a$ (representative), $4 b$ (transition), and $8 c$ (inner transition) axes ( $\alpha$-clusters) bound with valence neutrons standing a core ( $1{ }^{\text {st }}$ period) of likely expanding in $\mathrm{Co}, \mathrm{Ni}, \mathrm{Rh}$, and $\mathrm{Pd}$, which was naturally within proton and neutron drop lines, and roughly able to fit in with nuclear fission phenomena, including $\alpha$-cluster decay. It was observed in analysis molecular structures that crosses nuclear, atomic, and molecular three levels, which provides a convenient way that will enable the nature of the periodic table promisingly to become easier understanding.
\end{abstract}

Keywords: periodic table, proton distribution, valence neutron, folding nuclei, nuclear core, nuclear fission.

\section{Introduction}

The periodic table with the elements accumulated today is well-known and plays a basic role in physical science. Its nature (shape, $Z$, the atomic number) that is bewildering was traditionally explained by Bohr (1913), an atomic periodicity, though about in the meantime it has been proven to result from the proton number (Moseley, 1913). This seems possible to attribute to that a real cubic distribution of $Z$ in a nucleus might have not been revealed (Bohr \& Wheeler, 1939), to the author's knowledge. However, it may be a flaw to pay little attention on the proton number that could convey a nuclear periodicity to some extent. For example, magic nuclei 2, 8, 20, 28, 50, 82, and 126 (Haxel, Jensen, \& Suess, 1949) are almost inconsistent with noble nuclei (gases) 2, 10, 18, 36, 54, 86, and 118 , while noble nuclei appear to close naturally that can display a cubic $Z$.

It was observed in analysis molecular structure starting from a curiosity that whether an atomic mass has an influence upon molecular bond energy about in the summer of 1987 . Because an element occurs some isotopes and then had no intention of taking their relative mass what want to see nucleons how to distribute in a molecule (atom), every element is represented by its maximal abundant isotope selected from U.S. National Nuclear Data Center, (Nudat 2). Actually, it was an integrative result of atomic dot structure of Lewis, (1916) and nuclear alpha particle model (Hafstod \& Teller, 1938) plus valence neutrons (Table 1, Figures 1a-c and 2a-b, most notes in their captions).

To test this there is an attempt to interpret fission, mainly concentrating on fragment origin and yield, as it can direct reflect details of a nuclear structure. Furthermore, it tends to consider that $\alpha$ and cluster (nucleon number, $A$ $>4$ ) decay (Rose \& Jones, 1984) were similar to fission (like super asymmetric fission) (Poenaru, Ivascu, \& Sandulescu, 1979), despite indirect somewhat. Therefore, at this stage that their roots remain poorly understood a brief interpretation may be effectual. In the following, basic, light, mid, and heavy nuclei individually in the 1, 23, 4-5, and 6-7 (periods/layers) steps will be illustrated to emerge different shapes and folding. 
a)

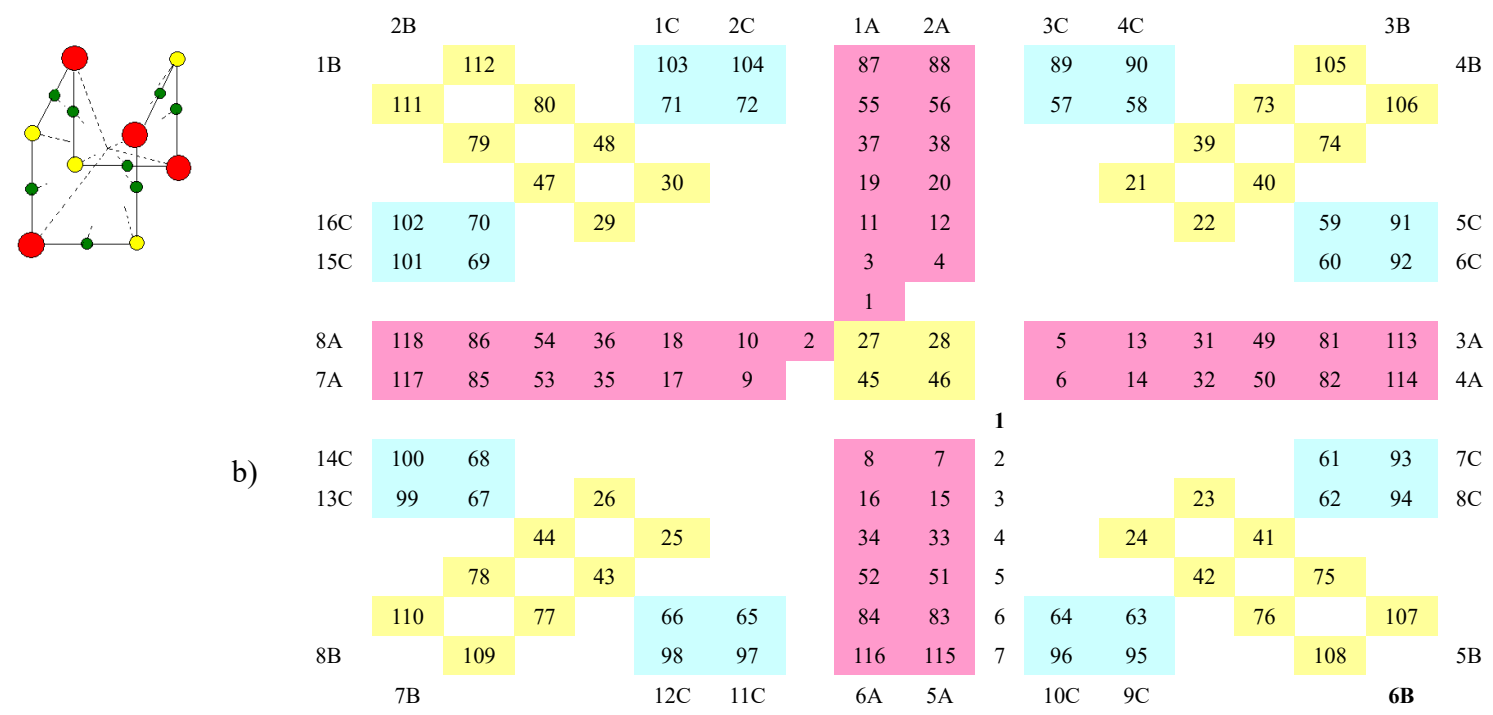

c)

\begin{tabular}{|c|c|c|c|c|c|c|c|c|c|c|c|c|c|c|c|c|c|c|}
\hline & $1 \mathrm{~A}$ & $2 \mathrm{~A}$ & $3 \mathrm{~B}$ & 4B & $5 \mathrm{~B}$ & $6 \mathrm{~B}$ & $7 \mathrm{~B}$ & $8 \mathrm{~B}$ & 9B & 10B & 1B & $2 \mathrm{~B}$ & $3 \mathrm{~A}$ & $4 \mathrm{~A}$ & $5 \mathrm{~A}$ & $6 \mathrm{~A}$ & $7 \mathrm{~A}$ & $8 \mathrm{~A}$ \\
\hline 1 & 1 & & & & & & & & & & & & & & & & & 2 \\
\hline 2 & 3 & 4 & & & & & & & & & & & 5 & 6 & 7 & 8 & 9 & 10 \\
\hline 3 & 11 & 12 & & & & & & & & & & & 13 & 14 & 15 & 16 & 17 & 18 \\
\hline 4 & 19 & 20 & 21 & 22 & 23 & 24 & 25 & 26 & 27 & 28 & 29 & 30 & 31 & 32 & 33 & 34 & 35 & 36 \\
\hline 5 & 37 & 38 & 39 & 40 & 41 & 42 & 43 & 44 & 45 & 46 & 47 & 48 & 49 & 50 & 51 & 52 & 53 & 54 \\
\hline 6 & 55 & 56 & 73 & 74 & 75 & 76 & 77 & 78 & & & 79 & 80 & 81 & 82 & 83 & 84 & 85 & 86 \\
\hline 7 & 87 & 88 & 105 & 106 & 107 & 108 & 109 & 110 & & & 111 & 112 & 113 & 114 & 115 & 116 & 117 & 118 \\
\hline & & & $3 \mathrm{C}$ & $4 \mathrm{C}$ & $5 \mathrm{C}$ & $6 \mathrm{C}$ & $7 \mathrm{C}$ & $8 \mathrm{C}$ & $9 \mathrm{C}$ & $10 \mathrm{C}$ & $11 \mathrm{C}$ & $12 \mathrm{C}$ & $13 \mathrm{C}$ & $14 \mathrm{C}$ & $15 \mathrm{C}$ & $16 \mathrm{C}$ & $1 \mathrm{C}$ & $2 \mathrm{C}$ \\
\hline & & & 57 & 58 & 59 & 60 & 61 & 62 & 63 & 64 & 65 & 66 & 67 & 68 & 69 & 70 & 71 & 72 \\
\hline & & & 89 & 90 & 91 & 92 & 93 & 94 & 95 & 96 & 97 & 98 & 99 & 100 & 101 & 102 & 103 & 104 \\
\hline
\end{tabular}

Figure 1. Nuclear folded and unfolded frames. (a) Red, yellow, and green are $4 a, 4 b$, and $8 c$ axes ( $\alpha$-clusters), where are $\mathrm{p}_{1}$ (last proton) locations of representative, transition, and inner transition elements, respectively. (b) Four $\mathrm{p}_{1}(Z=27,28,45$, and 46) were sunk into the 1 st period in old group 8B (American convention; groups 8-

10 , modern form), which was revised into groups 8-10B. (c) As $8 c \alpha$-clusters occupy $16 \mathrm{p}_{1}$, inner transition elements were suggested to increase from $2 \times 14$ to $2 \times 16$, then groups $8-10 \mathrm{~B}$ only leave ${ }_{78} \mathrm{Pt}$ and ${ }_{110} \mathrm{Ds}$. ${ }_{71} \mathrm{Lu}$ and ${ }_{72} \mathrm{Hf}$ of groups $1-2 \mathrm{C}$ into inner transition is following ${ }_{29} \mathrm{Cu}$ and ${ }_{30} \mathrm{Zn}$ of groups $1-2 \mathrm{~B}$ into transition, though inner transition shell has been closed at ${ }_{70} \mathrm{Yb}$ in Table 1

\section{Nuclear 4 steps and 16 Axes}

Basic nuclei ${ }^{1,2,3} \mathrm{H},{ }^{3,4} \mathrm{He}$, neutron, and di-neutrons appear in nuclei that can be separated into core, middle, and skin, core + middle $=c_{m}$; skin particle, $s_{p}$, its particle structures and distributions was called skin configuration. Collectively, $\mathrm{c}_{\mathrm{m}}$ is a noble nucleus and core is a ${ }^{4} \mathrm{He}$ in range $Z=3-26$, for it will expand in $Z=27$. On the other hand, in nuclear growth a nucleon behavior seems to loom up a tetrahedral shape having some "nucleon valence" $(\sim 4)$ to bind other nucleons or basic nuclei (Figure $2 a)$ with an explicit direction, suggesting that a molecular bond may result essentially from this character (Figure $2 b$ ).

In $\mathrm{F}_{2}, \mathrm{O}_{2}$, and $\mathrm{N}_{2}$ molecules, a single, double, and triple bond coincided with a pair of $\mathrm{t}$ in $\left({ }^{19} \mathrm{~F}^{4443}\right)_{2}$, two pairs of $\mathrm{d}$ in $\left({ }^{16} \mathrm{O}^{4242}\right)_{2}$, and three pairs of $\mathrm{d}$ in $\left({ }^{14} \mathrm{~N}^{4222}\right)_{2}$ suggest that molecular different shapes were rooted in skin configurations. Generally, skin configuration is corresponding to chemical main valence (Table 1), which is nearly the same as Lewis dot structure. For example, in ${ }^{16} \mathrm{O}_{\mathrm{c}-2+2}{ }^{4242}, 2$ dots and 2 lone pairs of electrons will identify with $2 \mathrm{~d}$ and $2 \alpha$; if $2{ }^{1,2,3} \mathrm{H}$ atoms descended on the $2 \mathrm{~d}$ extended lines, it is a ${ }^{1} \mathrm{H}_{2}{ }^{16} \mathrm{O}$ (Figure $2 \mathrm{~b}$ ), ${ }^{2} \mathrm{H}_{2}{ }^{16} \mathrm{O}$, or ${ }^{3} \mathrm{H}_{2}{ }^{16} \mathrm{O}$, providing a possibility to reassess that a reaction was between chemical and nuclear in water (Jones et al., 1989). At near the 2-3 step end, nuclei begin to grow $n_{v}$ that first clearly to emerge $4 n_{v}$ will be in ${ }^{40} \operatorname{Ar}_{\mathrm{v}-4}{ }^{4444}(99.59 \%$; $\left.{ }^{38} \mathrm{Ar}_{\mathrm{v}-2}{ }^{4444}, 0.063 \% ;{ }^{36} \mathrm{Ar}^{4444}, 0.337 \%\right)$ in natural nuclei $(\sim 300)$, where the $4 \mathrm{n}_{\mathrm{v}}$ position is to grow $4 b \alpha$-clusters. 
Table 1. A periodic distribution of nucleons for the maximal abundant isotopes

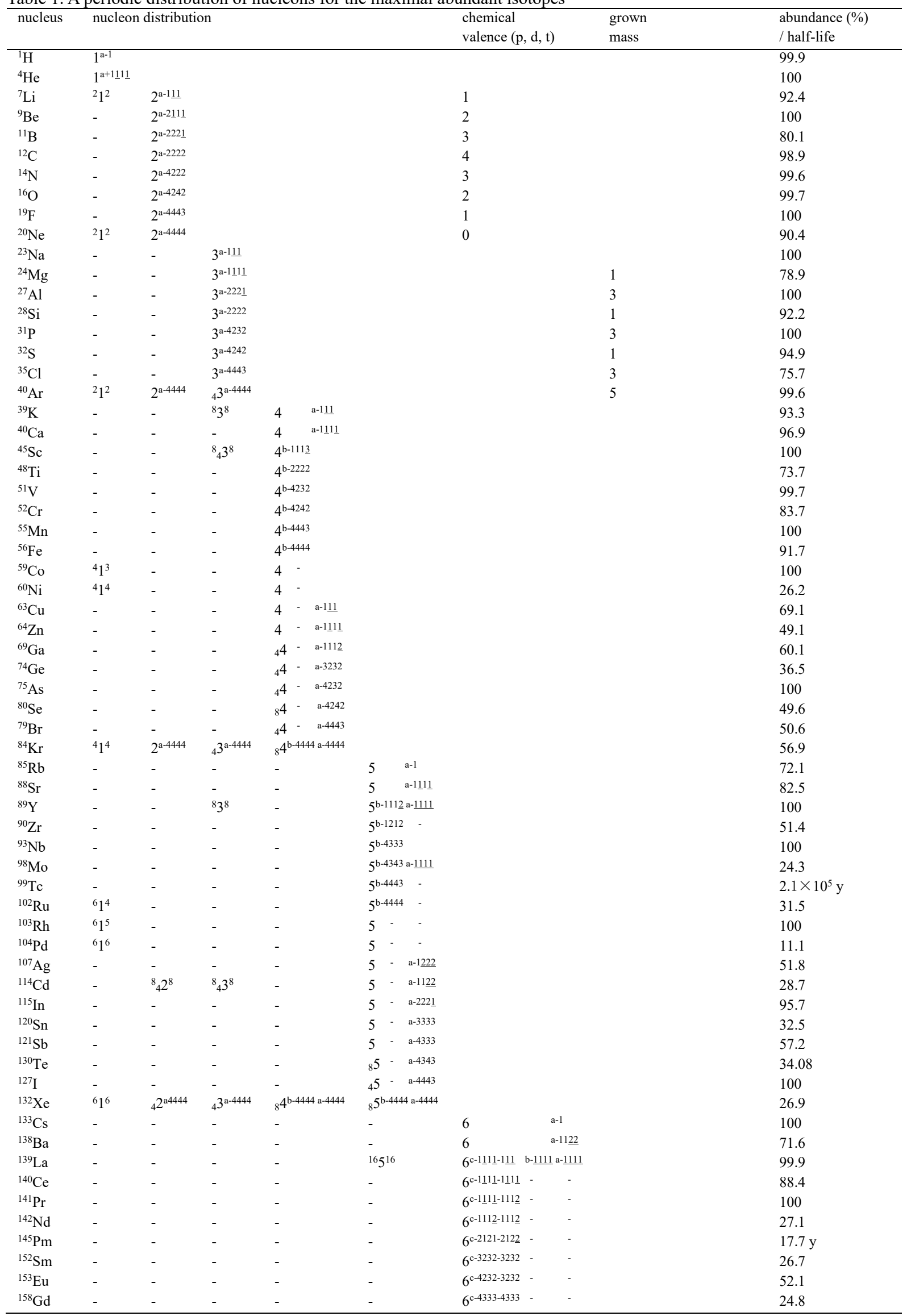




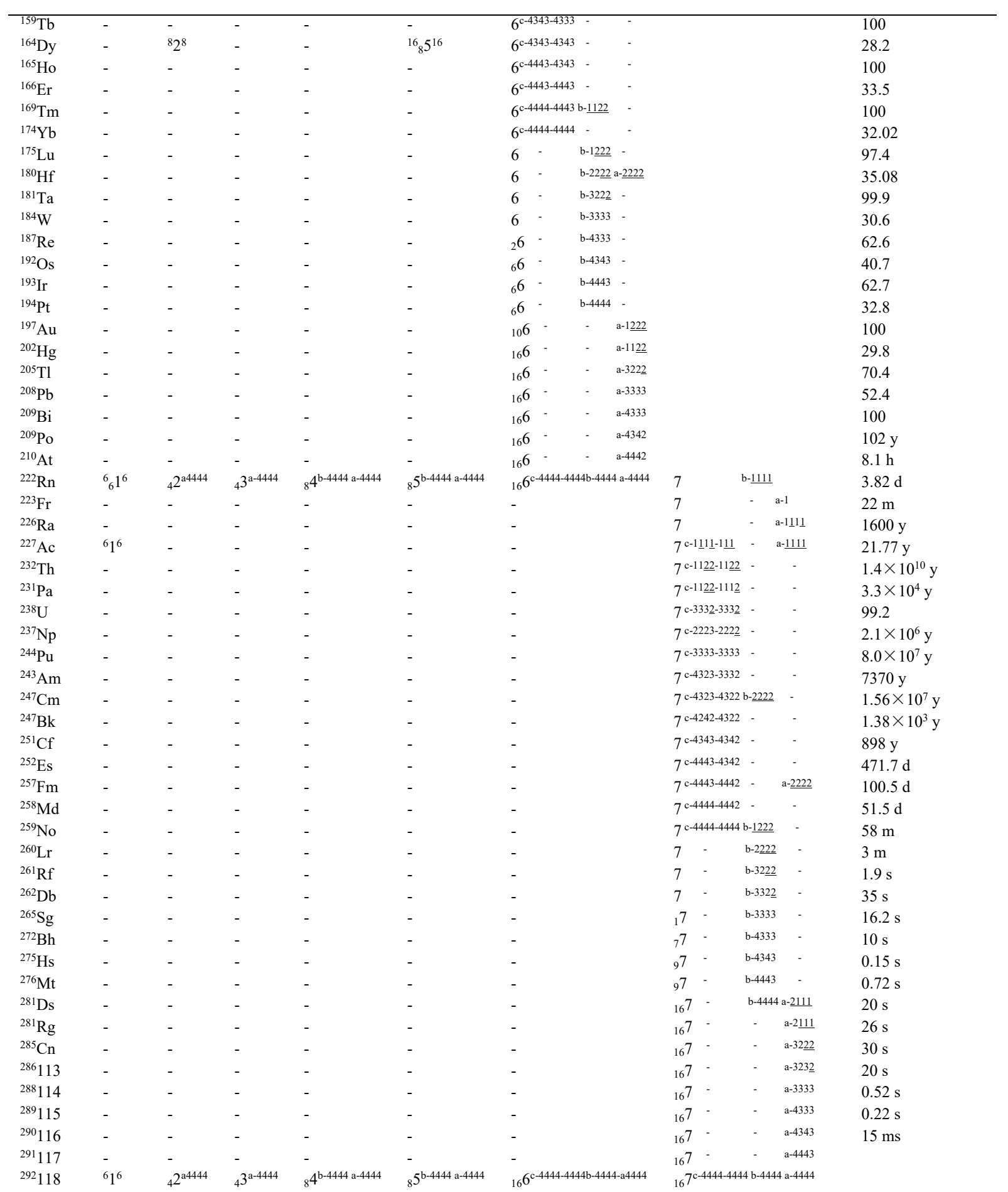

Subscript, left and right superscript of periodic number are the numbers of $\mathrm{n}_{\mathrm{v}}, \mathrm{n}_{\mathrm{p}}$ and $\mathrm{p}_{\mathrm{l}}$ respectively, and skin is 4 $a, 4 b$, and $8 c$ axes in 7 codes: 1 , proton (p); 2 , deuteron (d); 3 , triton (t); 4 , alpha particle $(\alpha) ; \underline{1}$, neutron (n); 2 , di-neutrons; $\underline{3},{ }^{3} \mathrm{He}$ ion. Single hyphen (-) is the same as upside. Chemical valence is in the $2^{\text {nd }}$ period and in the $3^{\text {rd }}$ period is grown mass between these nuclei. There will be a fluctuation only if ${ }^{58} \mathrm{Ni}(67.88 \%)$ and ${ }^{106} \mathrm{Pd}(27.33 \%)$ in group 10B are listed.

Along with nuclear crystal growing to the $4^{\text {th }}$ layer, its skin area will increase enough to hold another $4 b \alpha$-clusters in between $4 a \alpha$-clusters; further, its core will be intensified in old group 8B to support increasing mass. In terms of electron distributions, a proton distribution of ${ }_{21} \mathrm{Sc}$ is $2 \mathrm{p}_{1}$ of ${ }_{19} \mathrm{~K}$ and ${ }_{20} \mathrm{Ca}$ on $2 a$ axes, and $\mathrm{p}_{1}$ of ${ }_{21} \mathrm{Sc}$ on $b$ axis, but it seems to be questionable for nucleon arrangements of subsequent elements; i.e., $3 \mathrm{p}_{1}$ of ${ }_{19} \mathrm{~K},{ }_{20} \mathrm{Ca}$, and ${ }_{21} \mathrm{Sc}$ may 
simultaneously glide upon $b$ axes. In comparison, a pair distributions of electrons and protons is ${ }_{21} \mathrm{Sc}-\mathrm{e}(18) \mathrm{ds} \mathrm{s}^{2} / \mathrm{p}(18) \mathrm{d}^{3}$ (in proton distributions, $a=\mathrm{s}+\mathrm{p}$ that in range $Z=3-26,2 \mathrm{p}$ and $2 \mathrm{n}$ of basal tetrahedral $\alpha$-particle that $4 a$ axes stand on have not been distinguished, $b=\mathrm{d}$, and $c=\mathrm{f}$, respectively). Furthermore, $4 \mathrm{p}_{1}$ of ${ }_{27} \mathrm{Co},{ }_{28} \mathrm{Ni}{ }_{45} \mathrm{Rh}$, and ${ }_{46} \mathrm{Pd}$ will sink into the core (Figure $1 \mathrm{~b}$ ), which may be ended that a total of $6 \mathrm{p}_{1}(Z=1,2,27,28,45$, and 46) with $6 \mathrm{n}$ are to form an innermost close-packed core (Figure 2a). However, this performance will enable a nucleus to possess a definite hub, a Coulomb repulsion center, otherwise its shape cannot be opened, like a tiny liquid drop. Parallel to this was that per nucleon binding energy $\sim 8.7 \mathrm{MeV}$ is maximal, as nuclear mass increase to $A \sim 60$ (Nudat 2), which would imply that though at $\mathrm{Fe}-\mathrm{Co}-\mathrm{Ni}$ region nuclear core has been intensified immediately, a sharp change of nucleon distributions, its curve remains to fall from $\mathrm{Fe}$, a last element owning c-2+2 that may play a critical role in chemical element distributions of universe. Additionally, ferromagnetic only occurs in $\mathrm{Fe}, \mathrm{Co}$, and $\mathrm{Ni}$ at room temperature that possibly has a link to a structure and vibratory pattern of their nuclei.

a)

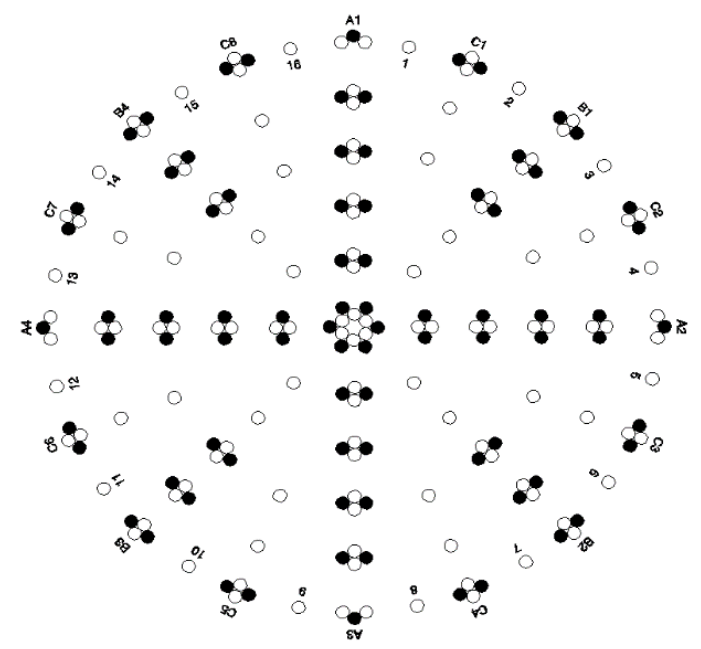

b)

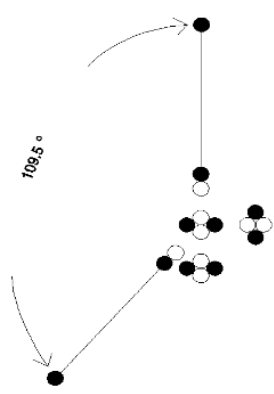

Figure 2. A crystal images of ${ }^{208} \mathrm{~Pb}$ (unfolded) and ${ }^{1} \mathrm{H}_{2}{ }^{16} \mathrm{O}$. (a) Closed and open circles are protons and neutrons. In ${ }^{208}{ }_{82+86+40} \mathrm{~Pb}_{\mathrm{c}-6+6, \mathrm{v}-4,4,8,8,16}{ }^{\mathrm{c}-4444-4444, \mathrm{~b}-4444, \mathrm{a}-3333}$, right superscript is skin configuration, subscript c- $6+6$ is core $(n+p), v-4,4,8,8,16$ is $n_{v}$ number in the 2-6 layers, and $82+86+40$ is $Z+n_{p}+n_{v}$ three shells, where $n_{p}$ is pair neutron, and $n_{v}$ is valence neutron (single open circles) to fill gaps in axes and layers. A nuclear coordinate was introduced to describe fission that the serial numbers of axes and layers are after $a, b$, and $c$ letters; for valence neutron is $n$ that it is clockwise rotating from $a 1$ axis to the origin point: $1 \rightarrow 4,1 \rightarrow 8$, and $1 \rightarrow 16$ in the $2-3,4-5$, and 6-7 steps, respectively. This figure suggests that in 1-1/4-8 fission (from $n 1-6$ through $1 / 4$ core to $n 8-6$ ), 1-8 and 8-1 sectors are light $\left(\mathrm{A}_{\mathrm{L}}\right)$ and heavy $\left(\mathrm{A}_{\mathrm{H}}\right)$ fragments, some of $6 \mathrm{n}_{\mathrm{v}}(n 1-6,1-4,1-2$ and $n 8-6,4-4,2-2)$ became prompt neutrons in the split line, and angular distributions of $\alpha$-particle were $90-22.5^{\circ}$ for $\mathrm{A}_{\mathrm{L}}$ and $90+22.5^{\circ}$

for $\mathrm{A}_{\mathrm{H}}$ coming from $c 1-6$ or $c 4-6$. (b) In the center is a ${ }^{16} \mathrm{O}_{\mathrm{c}-2+2}{ }^{4242}$ and the farthest are $2{ }^{1} \mathrm{H}$, suggesting that its chemical valence and their angle are rooted in the $2 \mathrm{~d}$. If $2 \mathrm{~d}$ of ${ }^{16} \mathrm{O}^{4242}(99.757 \%)$ were replaced by 1 or $2 \mathrm{t}$, it is

$$
{ }^{17} \mathrm{O}^{4342}(0.038 \%) \text { or }{ }^{18} \mathrm{O}^{4343}(0.205 \%)
$$

One of extraordinary feature in the periodic table is old group $8 \mathrm{~B}$ existence, implying that nuclei contain an expansible core, the other is the number of inner transition metals, from where a particular place, ${ }_{57} \mathrm{La}-\mathrm{e}(54) \mathrm{ds} \mathrm{s}^{2} / \mathrm{p}(54) \mathrm{f}^{3}$, start to grow out between $4 a$ and $4 b \alpha$-clusters, implying that nuclei are folding. The extrapolation is that, if inner transition $\mathrm{p}_{1}$ were on 6 faces or 12 sides of Figure 1a, it needs 12 or $24 \mathrm{p}_{\mathrm{l}}$, what is both impractical. Thus, it may averagely vacate 4 of 12 sides to grow 16 elements. On the other hand, whether inner transition contains 14 elements? If so, given that $\alpha$ is one of particles to construct a nucleus, as such an odd number of $7 \alpha$ will be asymmetric in a nuclear shape (coordinate). So far, it is thought that nuclear shapes might have not been so easy to recognize, whereas in here are visible that almost are tetrahedral in the $2-3$ step $\left({ }^{12} \mathrm{C},{ }^{28} \mathrm{Si}\right)$ and cubic in the $4-5$ step $\left({ }^{74} \mathrm{Ge},{ }^{120} \mathrm{Sn}\right)$, but in the $6-7$ step $\left({ }^{208} \mathrm{~Pb}\right)$, their shapes would be kept in a phase between cubic and flat, which might relate to a nuclear vibratory form. In fact, originally this nuclear pattern was two dimensional using Go game stones to put on the floor, however, it was so coincidental that when it was folded into three dimensional.

Folding nuclei were suggested from the 16 axes that in Table 1 show to correspond to the groups, which is almost same in a tri-group, regardless of group A, B, and C, such as skin configuration 4443 in tri-group 7 (7A, 7B, 1314C: ${ }^{165} \mathrm{Ho}^{\mathrm{c}-4443-4343}$ and $\left.{ }^{166} \mathrm{Er}^{\mathrm{c}-4443-4443}\right)$. In tri-group 3, a di-neutrons may serve as a proton in skins of ${ }^{45} \mathrm{Sc}$ and ${ }^{89} \mathrm{Y}$ in $3 \mathrm{~B}$ that each of them has $3 \mathrm{p}_{1}$ to stay on 3 of $4 b$ axes, then a di-neutrons will substitute for a proton to occupy a surplus axis to form a stable $b$-tetrahedron out of their $\mathrm{c}_{\mathrm{m}}$, i.e., ${ }^{40} \mathrm{Ar}+\mathrm{b}-111 \underline{2}\left({ }^{45} \mathrm{Sc}, 100 \%\right)$ and ${ }^{84} \mathrm{Kr}+\mathrm{b}-111 \underline{2}\left({ }^{89} \mathrm{Y}\right.$, 
$100 \%$ ). In stable nuclei, ${ }^{45} \mathrm{Sc}$ is likely emerging di-neutrons for the first time, which seems a unique structure that its proton distribution differs with of electron, as earlier mentioned. In group $1 \mathrm{~A}$, a ${ }^{7} \mathrm{Li}(92.5 \%)$ may prefer a- 111 to a-3 (a single triton) in its skin, including below ${ }^{23} \mathrm{Na}^{111}(100 \%),{ }^{39} \mathrm{~K}^{111}(93.3 \%),{ }^{87} \mathrm{Rb}^{111}(27.83 \%),{ }^{135} \mathrm{Cs}{ }^{111}$ $\left(2.3 \times 10^{6} \mathrm{y}\right)$, and ${ }^{225} \mathrm{Fr}^{111}(3.95 \mathrm{~m})$, because skin particle masses will smoothly increase from 1 to 4 along with sweeping tri-groups from $1(1 \mathrm{~A}, 1 \mathrm{~B}, 1-2 \mathrm{C})$ to $8(8 \mathrm{~A}, 8-10 \mathrm{~B}, 15-16 \mathrm{C})$. Apparently, there is a correspondence between atomic and nuclear periodicity, such as a-4443 in ${ }^{19} \mathrm{~F},{ }^{35} \mathrm{Cl},{ }^{79} \mathrm{Br}$, and ${ }^{127} \mathrm{I}$ in group 7A that all their chemical main valence is 1 . Perhaps, it cannot be excluded that the element properties were related to that long $a$, mid $b$, and short $c$ axes extend a different depth in nuclei (Figure 2a). For example, lanthanide contraction may be relevant to inner transition $16 \mathrm{p}_{1}$ trapped in $8 c$ axes where is low lying between $4 a$ and $4 b$ axes. Also, in ${ }^{23} \mathrm{Na}^{35} \mathrm{Cl}$, thin a111 in ${ }^{23} \mathrm{Na}\left({ }^{20} \mathrm{Ne}+\mathrm{a}-111\right)$ may be looser to its ${ }^{\mathrm{m}} \mathrm{c}$ than thick a-4443 in ${ }^{35} \mathrm{Cl}\left({ }^{20} \mathrm{Ne}+\mathrm{a}-4443\right)$, somewhat like that nucleon halo, if involved nuclear force, a factor possible influence on their atomic radii $(0.15$ and $0.09 \mathrm{~nm})$, implying that nuclear radii might link to atomic radii.

\section{Valence Neutron}

General in a nucleus, neutrons exceed protons in number, as the slope of beta stable line plotting in a chart (Nudat 2), suggesting obeyed

$$
A=Z+\mathrm{n}_{\mathrm{p}}+\mathrm{n}_{\mathrm{v}}
$$

where $\mathrm{n}_{\mathrm{v}}=2\left(2^{2}, 2^{3}, 2^{4}\right)$ are valence neutron holes in the 2-3, 4-5, and 6-7 steps of nuclei, respectively (Figure 2a), e.g. ${ }^{132} \mathrm{Xe}=54+54+2\left(2^{2}+2^{3}\right)$. Also, $\mathrm{n}_{\mathrm{v}}$ approximates to $\alpha$, e.g., ${ }^{132} \mathrm{Xe}=24\left(\mathrm{n}_{\mathrm{v}}+\alpha\right)+{ }_{6} 12$, where ${ }_{6} 12$ is its core in ${ }_{Z} A$; the ${ }_{6} 12$ might be replaced by a ${ }_{6} 18$ in ${ }^{222} \mathrm{Rn}$ (Table 1 ). Commonly, isotopic mass change for light nuclei was $\mathrm{n}_{\mathrm{p}}$ as ${ }^{16,17,18} \mathrm{O}$ in Figure 2b. For mid nuclei, e.g., ${ }^{112} \mathrm{Sn}_{\mathrm{v}-12}{ }^{2222}$ and ${ }^{124} \mathrm{Sn}_{\mathrm{v}-20}{ }^{3333}$, both their $\mathrm{n}_{\mathrm{p}}$ and $\mathrm{n}_{\mathrm{v}}$ were varied (Table 2). In Table 1 grown masses show a regular phenomenon that $1,3,1,3,1,3$, and 5 in the $3^{\text {rd }}$ period, when grow from odd to even $Z$, only fill $1 \mathrm{p}_{1}\left({ }^{23} \mathrm{Na}^{111} \rightarrow{ }^{24} \mathrm{Mg}^{11} \underline{1}\right)$ or with $4 \mathrm{n}_{\mathrm{v}}\left({ }^{35} \mathrm{Cl}^{4443} \rightarrow{ }^{40} \mathrm{Ar}_{\mathrm{v}-4}{ }^{4444}\right)$, but 1 p is often accompanied by $2 \mathrm{n}_{\mathrm{p}}\left({ }^{28} \mathrm{Si}^{2222} \rightarrow{ }^{31} \mathrm{P}^{4232}\right)$ from even to odd $Z$.

Table 2. A tentative nucleon arrangement of ${ }^{99-138} \mathrm{Sn}$

\begin{tabular}{|c|c|c|c|c|c|}
\hline \multirow{2}{*}{$\begin{array}{l}\text { Sn } \\
\text { nuclide }\end{array}$} & \multirow[b]{2}{*}{$\mathrm{c}_{\mathrm{m}}$} & \multirow[b]{2}{*}{$\mathrm{n}_{\mathrm{v}}$} & \multicolumn{2}{|c|}{ skin configuration } & \multirow{2}{*}{$\begin{array}{l}\text { abundance (\%) } \\
/ \mathrm{T}_{1 / 2}\end{array}$} \\
\hline & & & $\mathrm{b}$ & $\mathrm{a}$ & \\
\hline 99 & 76 & $0,0,3$ & 4444 & 1111 & \\
\hline 100 & - & $0,0,4$ & - & 1111 & $0.86 \mathrm{~s}(\varepsilon, \varepsilon p)$ \\
\hline 101 & - & $0,0,5$ & - & - & $1.7 \mathrm{~s}(\varepsilon, \varepsilon p)$ \\
\hline 102 & - & $0,0,6$ & - & - & $3.8 \mathrm{~s}(\varepsilon)$ \\
\hline 103 & - & $0,0,7$ & - & - & $7.0 \mathrm{~s}(\varepsilon, \varepsilon p)$ \\
\hline 104 & - & $0,0,8$ & - & - & $20.8 \mathrm{~s}(\varepsilon)$ \\
\hline 105 & - & $0,0,8$ & - & 2111 & $32.7 \mathrm{~s}(\varepsilon, \varepsilon p)$ \\
\hline 106 & - & $0,0,8$ & - & 2211 & $115 \mathrm{~s}(\varepsilon)$ \\
\hline 107 & - & $0,0,8$ & - & 2221 & $2.90 \mathrm{~m}(\varepsilon)$ \\
\hline 108 & - & $0,0,8$ & - & 2222 & $10.30 \mathrm{~m} \mathrm{( \varepsilon )}$ \\
\hline 109 & - & $0,1,8$ & - & - & $18.0 \mathrm{~m}(\varepsilon)$ \\
\hline 110 & - & $0,2,8$ & - & - & $4.11 \mathrm{~h}(\varepsilon)$ \\
\hline 111 & - & $0,3,8$ & - & - & $35.3 \mathrm{~m}(\varepsilon)$ \\
\hline 112 & - & $0,4,8$ & - & - & 0.96 \\
\hline 113 & - & $0,4,8$ & - & 3222 & $115.09 \mathrm{~d}(\varepsilon)$ \\
\hline 114 & - & $0,4,8$ & - & 3322 & 0.66 \\
\hline 115 & - & $0,4,8$ & - & 3332 & 0.34 \\
\hline 116 & - & $0,4,8$ & - & 3333 & 14.54 \\
\hline 117 & - & $1,4,8$ & - & - & 7.68 \\
\hline 118 & - & $2,4,8$ & - & - & 24.22 \\
\hline 119 & - & $3,4,8$ & - & - & 8.59 \\
\hline $119 \mathrm{~m}$ & - & $4,4,8$ & - & 3332 & $291.1 \mathrm{~d}$ (IT) \\
\hline 120 & - & $4,4,8$ & - & 3333 & 32.58 \\
\hline 121 & - & $4,4,8,1$ & - & - & $27.03 \mathrm{~h}\left(\beta^{-}\right)$ \\
\hline $121 \mathrm{~m}$ & - & $3,4,8,2$ & - & - & 43.9 y (IT) \\
\hline 122 & - & $4,4,8,2$ & - & - & 4.72 \\
\hline 123 & - & $4,4,8,3$ & - & - & $129.2 \mathrm{~d}\left(\beta^{-}\right)$ \\
\hline 124 & - & $4,4,8,4$ & - & - & 5.94 \\
\hline 125 & - & $4,4,8,5$ & - & - & $9.64 \mathrm{~d}\left(\beta^{-}\right)$ \\
\hline 126 & - & $4,4,8,6$ & _ & _- & $2.3 \times 10^{5} \mathrm{y}$ \\
\hline 127 & - & $4,4,8,7$ & - & - & $2.10 \mathrm{~h}\left(\beta^{-}\right)$ \\
\hline 128 & - & $4,4,8,8$ & - & - & $59.07 \mathrm{~m}\left(\beta^{-}\right)$ \\
\hline 129 & - & $4,4,8,8,1$ & - & - & $6.9 \mathrm{~m}\left(\beta^{-}\right)$ \\
\hline 130 & - & $4,4,8,8,2$ & _ & - & $3.72 \mathrm{~m}\left(\beta^{-}\right)$ \\
\hline 131 & - & $4,4,8,8,3$ & _ & _- & $56.4 \mathrm{~s}\left(\beta^{-}\right)$ \\
\hline 132 & - & $4,4,8,8,4$ & - & - & $39.7 \mathrm{~s}\left(\beta^{-}\right)$ \\
\hline 133 & - & $4,4,8,8,5$ & - & - & $1.46 \mathrm{~s}\left(\beta^{-}, \beta^{-} \mathrm{n}\right)$ \\
\hline 134 & - & $4,4,8,8,6$ & - & - & $1.05 \mathrm{~s}\left(\beta^{-}, \beta^{-} \mathrm{n}\right)$ \\
\hline 135 & - & $4,4,8,8,7$ & - & - & $530 \mathrm{~ms}\left(\beta^{-}, \beta^{-n}\right)$ \\
\hline 136 & - & $4,4,8,8,8$ & _ & _- & $0.25 \mathrm{~s}\left(\beta^{-}, \beta^{-} \mathrm{n}\right)$ \\
\hline 137 & - & $4,4,8,8,9$ & - & - & $190 \mathrm{~ms}\left(\beta^{-}, \beta^{-} \mathrm{n}\right)$ \\
\hline 138 & - & $4,4,8,8,10$ & - & - & $\sim 408 \mathrm{~ns}$ \\
\hline
\end{tabular}


In 39 neutrons $(138-99), \mathrm{n}_{\mathrm{v}} \sim 21, \mathrm{n}_{\mathrm{p}} \sim 8$, and $10 \mathrm{n}$ in the $6^{\text {th }}$ layer is neutron skin (halo). Valence neutrons in the 2-6 layers are compiled in a column. Decay modes: $\varepsilon$, electron capture; $p$, proton emission; IT, isomeric transition; $\beta^{-}$, beta-minus decay; $n$, neutron emission.

Admittedly, in many cases this primary neutron fit is alternative. For example, a ${ }^{36} \mathrm{~S}(0.014 \%)$ is ${ }^{36} \mathrm{~S}_{\mathrm{v}-4}{ }^{4242}$ or ${ }^{36} \mathrm{~S}_{\mathrm{v}-}$ ${ }_{2}^{4343}$ that how to balance $n_{p}$ and $n_{v}$, and $20 n_{v}$ of ${ }^{127} I$ is v- $0,4,8,8$ or v-4,4,8,4 (Table 1) in the 2-5 layers. Perhaps, in a nucleus neutron different distributions are correlated with nuclear isomers (Hahn, 1921) (marked m1, m2, m3...), while its proton shell is unconcerned; e.g., ${ }^{79} \mathrm{Br}_{\mathrm{v}-4,4}(50.69 \%)$ and ${ }^{79 m} \mathrm{Br}_{\mathrm{v}-0,0,8}(5.1 \mathrm{~s})$, or other distributions in the 24 layers (see also ${ }^{119 \mathrm{~m}, 121 \mathrm{~m}} \mathrm{Sn}$ in Table 2). However, ${ }^{12} \mathrm{C}^{2222}(98.93 \%),{ }^{13} \mathrm{C}^{3222}(1.07 \%),{ }^{14} \mathrm{C}^{3232}$ and ${ }^{28} \mathrm{Si}^{2222}(92.223 \%)$, ${ }^{29} \mathrm{Si}^{3222}$ (4.685\%), ${ }^{30} \mathrm{Si}^{3232}$ (3.092\%) demonstrate the higher abundance, the more concise structure.

Away from the beta stable line, ${ }^{3} \mathrm{He}$ was estimated to generate in skin of neutron-deficient light nuclei, e.g. ${ }^{19} \mathrm{Ne}_{\mathrm{c}-}$ ${ }_{2+2}{ }^{4443}(17.22 \mathrm{~s})$ and ${ }^{17} \mathrm{Ne}_{\mathrm{c}-2+2}{ }^{4333}(109.2 \mathrm{~ms})$. Moreover, a heavy nucleus lack of neutrons, $\mathrm{n}_{\mathrm{v}}$, to bind its vertical $a-$ $(5 \alpha), b-\left(3 \alpha,{ }^{12-15} \mathrm{C}\right.$, Rose \& Jones, 1984), and $c$ - $(1 \alpha)$ clusters may more easily cause decay, corresponding to the fact that $\alpha$-decay only happen in neutron-deficient heavy nuclei (excepting super heavy nuclei, in mid nuclei almost never, e.g. ${ }^{99-111} \mathrm{Sn}$ in Table 2) that begin to grow $c-1 \alpha$ clusters. Therefore, it seems difficult to distinguish $\alpha$-cluster decay and nuclear fission that only split ratios are different, if nuclei were a skeleton of $16 \alpha$-clusters (Table 3 ).

Toward neutron drop line, e.g., a structure of super large ${ }^{11} \mathrm{Li}^{2}{ }^{2}{ }^{2}, 2^{\mathrm{a}-2111}, 3 \frac{11}{}(8.75 \mathrm{~ms})$ might be a $\mathrm{c}_{\mathrm{m}}$ of ${ }^{9} \mathrm{Li}$ with a 2-neutron halo (CERN, 2004). Additionally, a neutron skin (halo) may happen in a stable nucleus; e.g., ${ }^{136} \mathrm{Xe}-$ ${ }^{6} 1{ }^{6},{ }_{4} 2^{8},{ }_{4}^{8} 3^{8},{ }_{8}^{16} 4^{16},{ }_{8}^{16} 5^{16}, 6^{1111}(8.9 \%)$, this $6^{1111}$ skin will cage a ${ }^{132} \mathrm{Xe}$, for its $\mathrm{n}_{\mathrm{p}}$ and $\mathrm{n}_{\mathrm{v}}$ shells have been closed.

Note that, unexpectedly, all of $Z, \mathrm{n}_{\mathrm{p}}$, and $\mathrm{n}_{\mathrm{v}}$ three shells filled up $\left(A=2 Z+\mathrm{n}_{\mathrm{v}}\right.$, ideal nucleus) shows not a most proper structure from two abundance $\left(\mathrm{T}_{1 / 2}\right)$ lines of ideal nuclei and their maximal abundant isotopes intersecting at ${ }^{132} \mathrm{Xe}_{\mathrm{v}-4,4,8,8}(26.9 \%)$, i.e., $\mathrm{n}_{\mathrm{v}}$ too many in ${ }^{24} \mathrm{Ne}_{\mathrm{v}-4}(3.38 \mathrm{~m}),{ }^{44} \mathrm{Ar}_{\mathrm{v}-4,4}(11.87 \mathrm{~m})$, and ${ }^{88} \mathrm{Kr}_{\mathrm{v}-4,4,8}(2.84 \mathrm{~h})$, but too few in ${ }^{212} \mathrm{Rn}_{\mathrm{v}-4,4,8,8,16}\left(23.9 \mathrm{~m}\right.$ ) and ${ }^{292} 118_{\mathrm{v}-4,4,8,8,16,16}$ (?). Nevertheless, here was unable to find a better way to fit pair and valence neutrons with the line of beta stability.

\section{Fission Outlines}

On the whole, fission fragments seem to agree with nuclear $16 \alpha$-clusters splitting into different ratios (Table 3). Relatively complicated is to consider a possible skin particle glide in asymmetric fission. Here a mode is taking a fragment to be a mixture of $c_{m}$ and $s_{p}$ partly. For example, in 1-1/4-8 fission of ${ }^{235} U+n$, its $c_{m}$ is lined off:

$$
{ }^{212} \mathrm{Rn}_{1-1 / 4-8} \rightarrow{ }_{53} 129+{ }_{33} 83,
$$

and its $\mathrm{s}_{\mathrm{p}}$ falls into

$$
\mathrm{c}-222 \underline{2}, \mathrm{~b}-\underline{11}, \mathrm{a}-\underline{111}+\mathrm{c}-222 \underline{2}, \mathrm{~b}-\underline{11}, \mathrm{a}-\underline{1}={ }_{3} 13+{ }_{3} 11,
$$

then add Equations 3 to 2,

$$
\begin{gathered}
{ }^{235} \mathrm{U}+\mathrm{n}_{1-1 / 4-8} \rightarrow\left({ }_{53} 129+{ }_{3} 13\right)+\left({ }_{33} 83+{ }_{3} 11\right)={ }^{142} \mathrm{Ba}+{ }^{94} \mathrm{Kr}, \\
{ }^{235} \mathrm{U}+\mathrm{n}_{1-1 / 4-8} \rightarrow{ }_{53} 129+\left({ }_{33} 83+{ }_{6} 24\right)={ }^{129} \mathrm{I}+{ }^{107} \mathrm{Y}, \\
\left.{ }^{235} \mathrm{U}+\mathrm{n}_{1-1 / 4-8} \rightarrow{ }_{53} 129+{ }_{6} 24\right)+{ }_{33} 83={ }^{153} \mathrm{Pr}+{ }^{83} \mathrm{As},
\end{gathered}
$$

suggesting that a fragment peak yield (Thomas \& Vandenbosch, 1964) could be partly contributed from ${ }_{3} 13$ and ${ }_{3} 11$ glide, albeit likely, the higher shift ratio, the lower yield. In Equation $4 \mathrm{~s}$ has not glided that two fragment yields are $\sim 6 \%$ at peak. The valley is a symmetric fission:

$$
{ }^{235} \mathrm{U}+\mathrm{n}_{1-1 / 2-9} \rightarrow{ }_{46} 118+{ }_{46} 118,
$$

$\sim 0.1 \%$.

Comparing Equations 5 and 6 suggests that $s_{p}$ prefer to glide upon $A_{L}\left(3^{\mathrm{a}} 2^{\mathrm{b}} 4^{\mathrm{c}}: 1^{\mathrm{a}} 2^{\mathrm{b}} 4^{\mathrm{c}}+\mathrm{s}_{\mathrm{p}}\right)$, likely that it is to balance two fragment masses to rip a nucleus, for the yield of Equations 5 is roughly higher than 6 . This view is also illustrated in Fig. 1 of Unik et al., (1973) that $A_{H}$ masses are nearly constant, while $A_{L}$ masses increase in ${ }^{229} \mathrm{Th}$, ${ }^{233,235} \mathrm{U},{ }^{239} \mathrm{Pu},{ }^{245} \mathrm{Cm},{ }^{249} \mathrm{Cf}$, and ${ }^{254} \mathrm{Es}(\mathrm{n}, \mathrm{f})$. However, $\mathrm{s}_{\mathrm{p}}$ may glide to affect thermal neutron $(\mathrm{n}, \mathrm{f})$ and spontaneous (sf) asymmetric fission that transition from asymmetry to symmetry is about in two sides of $Z 94 \pm 6\left({ }_{88} \mathrm{Ra}-{ }_{100} \mathrm{Fm}\right)$ [Z $94=(86+102) / 2$, where 86 and 102 are representative and inner transition closed shells], implying that its mass number is neither too many, nor too few. For example, ${ }^{226} \mathrm{Ra}\left({ }^{3} \mathrm{He}, \mathrm{df}\right)$ simultaneously revealed asymmetric and symmetric fission (Konecny, Specht, \& Weber, 1973), and from ${ }^{254}{ }_{100+114+40} \mathrm{Fm}^{\mathrm{c}-4443-4443, \mathrm{~b}-2222, \mathrm{a}-1111}$ (sf, asymmetric) (Gindler, Flynn, Glendenin, \& Sjoblom, 1977) to ${ }^{258}{ }_{100+118+40} \mathrm{Fm}^{\mathrm{c}-4443-4443, \mathrm{~b}-2222, \mathrm{a}-2222}\left({ }^{257} \mathrm{Fm}+\mathrm{n}\right.$, symmetric) (Flynn, Gindler, \& Glendenin, 1975) a-1111 was replaced by a-2222 that is likely closed $\mathrm{n}_{\mathrm{p}}-118$ shell fenced against the 
$\mathrm{S}_{\mathrm{p}}$ glide. In the case of ${ }^{252}{ }_{102+110+40} \mathrm{No}^{\mathrm{c}-4444-4444, \mathrm{~b}-1111, \mathrm{a}-11111}$, despite its $Z-102$ shell closure, it is an asymmetric fission (Bemis et al., 1977), not impossible that it lacks $8 \mathrm{n}_{\mathrm{p}}$ than ${ }^{258} \mathrm{Fm}$ to resist the $\mathrm{s}_{\mathrm{p}}$ glide.

In addition, possible to result in even- $Z$ fragment that its energy release is greater than odd (fine structure of fragment masses, interval $A \sim 5, \mathrm{n}_{\mathrm{v}}+\alpha$ ) (Thomas \& Vandenbosch, 1964), part of $\mathrm{s}_{\mathrm{p}}$ might be fused in glide, since in ${ }^{235} \mathrm{U}(\mathrm{n}, \mathrm{f})$, its skin having no an innate $\alpha$-particle, has occurring polar $\alpha$-particle emission, about $0^{\circ}$ or $180^{\circ}$ with respect to the fission axis (Piasecki, Dakowski, Krogulski, Tys, \& Chwaszczewska, 1970). Moreover, the yield is over 3 times for $A_{L}$ to $A_{H}$ flight directions (Piasecki \& Nowicki, 1979), which is in favor of $s_{p}$ to glide upon $A_{L}$ again.

At leftmost bottom sides of a double peak curve, $A \sim 80$ and $\sim 130$, are two vanishing points of $\mathrm{A}_{\mathrm{L}}, \mathrm{A}_{\mathrm{H}}$ (Unik et al., 1973), neutron (Bowman, Milton, Thompson, \& Swiatecki, 1963), and $\alpha$-particle (Schmitt, Neiler, Walter, \& Chetham-Strode, 1962), which both point to a sector where its 2 edges are enclosed by long $2 a$ axes, i.e., $2^{\mathrm{a}} 1^{\mathrm{b}} 2^{\mathrm{c}}$ $\left(A_{L}\right)$ and $3^{\mathrm{a}} 2^{\mathrm{b}} 4^{\mathrm{c}}\left(\mathrm{A}_{\mathrm{H}}\right) \alpha$-clusters. Take neutron yields for example, in

$$
{ }^{252} \mathrm{Cf}_{1-1 / 4-8} \rightarrow{ }_{53} 129+\left({ }_{33} 83+{ }_{12} 40\right)={ }_{53} 129+{ }_{45} 123
$$

where ${ }_{53} 129$ is a minimal $3^{\mathrm{a}} 2^{\mathrm{b}} 4^{\mathrm{c}}$ and ${ }_{45} 123$ is a complementary $1^{\mathrm{a}} 2^{\mathrm{b}} 4^{\mathrm{c}}$ to yield maximal neutrons $(\sim 3)$ (Bowman, Milton, Thompson, \& Swiatecki, 1963), suggesting that maximal neutron yield is from a sector of short $2 c$ axis edges. In ${ }^{254} \mathrm{Fm}(\mathrm{sf})$ that both ${ }^{252} \mathrm{Cf}$ and ${ }^{254} \mathrm{Fm}$ neutron shells were $\mathrm{n}_{\mathrm{p}}-114+\mathrm{n}_{\mathrm{v}}-40$ shows a similar result of neutron yield: minimum at $A 129-130$ of $\mathrm{A}_{\mathrm{H}}$ and maximum at $A$ 123-124 of $\mathrm{A}_{\mathrm{L}}$ (Gindler, Flynn, Glendenin, \& Sjoblom, 1977).

Similarly, a neutron deficient fragment seems also relating to this. For instance, in ${ }^{238} \mathrm{U}+{ }^{12} \mathrm{C}$ (Delaune et al., 2013), a ${ }^{73}$ As may consist with ${ }_{30} 70+{ }_{3} 3$ in 4-1/4-9 fission, where $3070=5 \alpha \times 2+3 \alpha+1 \alpha \times 2+10 \mathrm{n}_{\mathrm{v}}$ and ${ }_{3} 3$ is from core. In ${ }^{238} \mathrm{U}+\mathrm{p}$ (Klingensmith, \& Porile, 1988), ${ }^{72} \mathrm{As}$ and ${ }^{69} \mathrm{Zn}$ might come from other ways, because the $10 \mathrm{n}_{\mathrm{v}}$ normally cannot be released inside a minimal $2^{\mathrm{a}} 1^{\mathrm{b}} 2^{\mathrm{c}}\left({ }^{70}{ }_{30} \mathrm{Zn}\right)$, unless one of them has become a delayed neutron (Amiel, 1969) that when the fragment was reconstituted to turn into a daughter nucleus.

However, $4 a, 4 b$, and $8 c \alpha$-clusters could set up different fission barriers that 2 of $4 a$ will be the biggest. On the other hand, a split line sweeps a single $c, b$, or $a$ axis that will create a new mass difference (Table 3 ). To an $a$ axis, it is, e.g.,

$$
{ }^{235} \mathrm{U}+\mathrm{n}_{1-1 / 2-8} \rightarrow\left({ }_{53} 126+{ }_{3} 13\right)+\left({ }_{33} 86+{ }_{3} 11\right)={ }^{139} \mathrm{Ba}+{ }^{97} \mathrm{Kr}=\left({ }_{46} 118+{ }_{10} 21\right)+\left({ }_{46} 118-{ }_{10} 21\right),
$$

where ${ }_{10} 21={ }_{10} 20+1$, a cluster of $5 \alpha$ (a3 axis) plus $1 \mathrm{n}$ at $a 3-7$ position, when the split line swept anticlockwise from 1-1/2-9 (Equation 7) to 1-1/2-8.

\begin{tabular}{|c|c|c|c|}
\hline \multirow{2}{*}{$\begin{array}{l}\text { fission } \\
\text { depth and path }\end{array}$} & \multirow{2}{*}{$\begin{array}{l}\text { split ratio of } \\
16 \alpha \text {-clusters }\end{array}$} & \multicolumn{2}{|c|}{$Z-A$ distribution } \\
\hline & & $\mathrm{A}_{\mathrm{L}}$ & $\mathrm{A}_{\mathrm{H}}$ \\
\hline $1-1 / 2-9$ & $2^{\mathrm{a}} 2^{\mathrm{b}} 4^{\mathrm{c}}: 2^{\mathrm{a}} 2^{\mathrm{b}} 4^{\mathrm{c}}(8: 8)$ & ${ }^{118} \mathrm{Pd}$ & ${ }^{118} \mathrm{Pd}$ \\
\hline $2-1 / 2-9$ & $2^{\mathrm{a}} 2^{\mathrm{b}} 3^{\mathrm{c}}: 2^{\mathrm{a}} 2^{\mathrm{b}} 5^{\mathrm{c}}(7: 9)$ & ${ }^{111} \mathrm{Tc}$ & ${ }^{125} \mathrm{In}$ \\
\hline $3-1 / 2-9$ & $2^{\mathrm{a}} 1^{\mathrm{b}} 3^{\mathrm{c}}: 2^{\mathrm{a}} 3^{\mathrm{b}} 5^{\mathrm{c}}(6: 10)$ & ${ }^{95} \mathrm{Rb}$ & ${ }^{141} \mathrm{Cs}$ \\
\hline $4-1 / 2-9$ & $2^{\mathrm{a}} 1^{\mathrm{b}} 2^{\mathrm{c}}: 2^{\mathrm{a}} 3^{\mathrm{b}} 6^{\mathrm{c}}(5: 11)$ & ${ }^{88} \mathrm{Se}$ & ${ }^{148} \mathrm{Ce}$ \\
\hline $1-1 / 4-8$ & $1^{\mathrm{a}} 2^{\mathrm{b}} 4^{\mathrm{c}}: 3^{\mathrm{a}} 2^{\mathrm{b}} 4^{\mathrm{c}}(7: 9)$ & ${ }^{94} \mathrm{Kr}$ & ${ }^{142} \mathrm{Ba}$ \\
\hline $2-1 / 4-8$ & $1^{\mathrm{a}} 2^{\mathrm{b}} 3^{\mathrm{c}}: 3^{\mathrm{a}} 2^{\mathrm{b}} 5^{\mathrm{c}}(6: 10)$ & ${ }^{85} \mathrm{As}$ & ${ }^{151} \mathrm{Pr}$ \\
\hline $3-1 / 4-8$ & $1^{\mathrm{a}} 1^{\mathrm{b}} 3^{\mathrm{c}}: 3^{\mathrm{a}} 3^{\mathrm{b}} 5^{\mathrm{c}}(5: 11)$ & ${ }^{69} \mathrm{Co}$ & ${ }^{167} \mathrm{~Tb}$ \\
\hline $4-1 / 4-8$ & $1^{\mathrm{a}} 1^{\mathrm{b}} 2^{\mathrm{c}}: 3^{\mathrm{a}} 3^{\mathrm{b}} 6^{\mathrm{c}}(4: 12)$ & ${ }^{60} \mathrm{Cr}$ & ${ }^{176} \mathrm{Er}$ \\
\hline $1-0-9$ & $2^{\mathrm{a}} 2^{\mathrm{b}} 4^{\mathrm{c}}: 2^{\mathrm{a}} 2^{\mathrm{b}} 4^{\mathrm{c}}(8: 8)$ & ${ }^{112} \mathrm{Tc}$ & ${ }^{124} \mathrm{In}$ \\
\hline $2-0-9$ & $2^{\mathrm{a}} 2^{\mathrm{b}} 3^{\mathrm{c}}: 2^{\mathrm{a}} 2^{\mathrm{b}} 5^{\mathrm{c}}(7: 9)$ & ${ }^{105} \mathrm{Zr}$ & ${ }^{131} \mathrm{Te}$ \\
\hline $3-0-9$ & $2^{\mathrm{a}} 1^{\mathrm{b}} 3^{\mathrm{c}}: 2^{\mathrm{a}} 3^{\mathrm{b}} 5^{\mathrm{c}}(6: 10)$ & ${ }^{89} \mathrm{Se}$ & ${ }^{147} \mathrm{Ce}$ \\
\hline $4-0-9$ & $2^{\mathrm{a}} 1^{\mathrm{b}} 2^{\mathrm{c}}: 2^{\mathrm{a}} 3^{\mathrm{b}} 6^{\mathrm{c}}(5: 11)$ & ${ }^{82} \mathrm{Ga}$ & ${ }^{154} \mathrm{Pm}$ \\
\hline \multicolumn{4}{|l|}{$\alpha$-cluster decay } \\
\hline $1-0-2$ & $: 4^{\mathrm{a}} 4^{\mathrm{b}} 7^{\mathrm{c}}(1: 15)$ & ${ }^{4} \mathrm{He}$ & ${ }^{232} \mathrm{Th}$ \\
\hline $2-0-3$ & $: 4^{\mathrm{a}} 3^{\mathrm{b}} 8^{\mathrm{c}}(1: 15)$ & ${ }^{12} \mathrm{C}$ & ${ }^{224} \mathrm{Rn}$ \\
\hline $4-0-5$ & $1^{\mathrm{a}} \quad: 3^{\mathrm{a}} 4^{\mathrm{b}} 8^{\mathrm{c}}(1: 15)$ & ${ }^{20} \mathrm{Ne}$ & ${ }^{216} \mathrm{~Pb}$ \\
\hline
\end{tabular}

Table 3. Some fission depths and paths of ${ }^{236} \mathrm{U}$.

A structure of ${ }^{236} \mathrm{U}$ was ${ }^{6} 16,{ }_{4} 2^{8},{ }_{4} 3^{8},{ }_{8}{ }^{16}{ }^{16},{ }_{8}^{16} 5^{16},{ }_{16}^{32} 6^{32}, 7^{\mathrm{c}-2222-2222, \mathrm{~b}-1111, \mathrm{a}-1111}$. Fission depth (different divide of core ${ }_{6} 12$ nucleons) was mainly classified into: $1 / 2,{ }_{3} 6: 36 ; 1 / 4,{ }_{3} 3: 39 ; 0,0: 612$. The $n_{v}$ number error is about \pm 3 in mass division, which could be related to isotopic products. In the split lines $\mathrm{s}_{\mathrm{p}}$ and $\mathrm{n}_{\mathrm{v}}$ have not been allotted to $\alpha$-cluster decay. 
A binary fission in Figure 2a could draw a line from one side through core to the opposite side. When draw three lines, e.g., 1-c (from $n 1-6$ to core), 2-c, and 9-c, it is a ternary 1-2-9 fission. Usually, 1-2 sector (one of $8 c$ axes) is a place of light charged particle (LCP) emission that can partition it into three points: $c 1-7$ (p, d, t, $\alpha), c 1-6(\alpha)$, and $c 1-6+c 1-7\left({ }^{7,8,9} \mathrm{Li},{ }^{9,10} \mathrm{Be}\right)$. LCP emission probabilities in per $10^{3} \mathrm{sf}$ of ${ }^{252} \mathrm{Cf}^{\mathrm{c}-4343-4343, \mathrm{~b}-2222, \mathrm{a}-1111}$ are: $\alpha-3.3, \mathrm{t}-0.2$, $\mathrm{d}-0.02$, and p-0.06, respectively (Wild et al., 1985), slightly less than ideal that its skin has $4 \alpha$ and $4 \mathrm{t}$, no $\mathrm{d}$ and $\mathrm{p}$, which might be able to serve as a probe to identify skin configurations. If the track varied from 1-2-9 to 1-4-8 randomly, it is a three large fragment fission (Muga, Rice, \& Sedlacek, 1967), in which ${ }^{235} \mathrm{U}(\mathrm{n}, \mathrm{f})$, three sectors are about 1-4 $\left({ }^{35} \mathrm{Mg}\right), 4-8\left({ }^{56} \mathrm{Sc}\right)$, and $8-1\left({ }^{145} \mathrm{Pr}\right)$. It therefore was sensible to deduce that lighter fragments most likely result from a different combination of $a, b$, and $c$ axes, e.g., $1^{\mathrm{c}}, A \sim 10, \mathrm{LCP} ; 1^{\mathrm{b}} 2^{\mathrm{c}}, A \sim 30,{ }^{28} \mathrm{Mg}$ (Iyer \& Cobble, 1966); $1^{\mathrm{a}} 1^{\mathrm{b}} 1^{\mathrm{c}}, A \sim 50,{ }^{47} \mathrm{Ca},{ }^{48} \mathrm{Sc}$ (Klingensmith, \& Porile, 1988). From here, naturally, it is tempting to expect that a nucleus might deeply be fragmented into four large fragments; e.g., in a quaternary 1-3-9-14 fission of ${ }^{235} \mathrm{U}+\mathrm{n}$, four sectors are 1-3 $\left({ }^{25} \mathrm{~F}\right), 3-9\left({ }^{93} \mathrm{Rb}\right), 9-14\left({ }^{69} \mathrm{Co}\right)$, and $14-1\left({ }^{49} \mathrm{~K}\right)$. However, four coincident fragment angular, energy, and mass distributions in a quaternary fission would shed light upon that whether a nuclear shape is from folded to unfolded in fission.

\section{Discussion}

To explain fission phenomena rely on what a nuclear model was based on. However, this work seems flexible to fit. Namely, a nuclear fission, asymmetric limited within $Z 94 \pm 6$ nuclei as a rule, is likely that its $16 \alpha$-clusters are splitting into different ratios from $15: 1\left(1^{\mathrm{c}}, \alpha\right.$ decay; $1^{\mathrm{b}}$ or $1^{\mathrm{a}}$, cluster decay, essentially similar to three large fragments in a fission) to $8: 8$ to produce different mass fragments, and $n_{v}$ in a split line will prevail over $n_{p}$ to convert prompt neutrons. For example, if $16 \alpha$-clusters were splitting into 9:7, a pair fragment mass difference is ${ }_{z} A \geqslant{ }_{20} 40( \pm 1 a$ axis, 2 clusters of $5 \alpha)$ in ${ }^{235} \mathrm{U}+\mathrm{n} \rightarrow{ }^{137} \mathrm{Ba}+{ }^{97} \mathrm{Kr}+2 \mathrm{n}$. In addition, among LCP most probable emission is $\alpha$ that its angle differs from polar emission is perpendicular to fission axis, nearly $90 \pm 22.5^{\circ}$ to $A_{H}$ and $A_{L}$, respectively, where $22.5^{\circ}=360^{\circ} / 16$. Since a fission nucleus is almost impossibly complete unfolded, its $\alpha$ emitting angle is within $67.5^{\circ}-112.5^{\circ}$ that came from one of inner transition $8 \alpha$-particles, which is satisfactorily in agreement with Fig. 9 of Fluss, Kaufman, Steinberg, and Wilkins (1973).

In addition, the yields of various fragments suggest to vanish in the same two points: $3^{\mathrm{a}} 2^{\mathrm{b}} 4^{\mathrm{c}}(A \sim 130)$ and $2^{\mathrm{a}} 1^{\mathrm{b}} 2^{\mathrm{c}}$ $(A \sim 80) \alpha$-clusters. Currently, fragment $A \sim 130$ and $A \sim 80$ were explained near $Z-50, N-82$ and $Z-28, N-50$ doubly magic shells, respectively, which seem that there has no a distinction of proton and neutron shells. Perhaps, their shells are the same only in magic number $2\left({ }^{4} \mathrm{He}\right), 8\left({ }^{16} \mathrm{O}\right)$, and $20\left({ }^{40} \mathrm{Ca}\right)($ Table 1$)$; for the 28,50 , and 82 , it is to differ because of valence neutron emergence. To $N-126$ shell in Figure $2 \mathrm{a}$ shows to derive from $\mathrm{n}_{\mathrm{p}}-86+\mathrm{n}_{\mathrm{v}}-40$, a frame to grow ${ }^{208}{ }_{82+86+40} \mathrm{~Pb}^{3333},{ }^{209} \mathrm{Bi}^{4333},{ }^{210} \mathrm{Po}^{4343},{ }^{211} \mathrm{At}^{4443}$, and ${ }^{212}{ }_{86+86+40} \mathrm{Rn}^{4444}$. Though only $Z-2, N-2, Z-28$, and $N-126$ shells are closed here (even if completely closed ideal nuclei are not most stable, except ${ }^{132} \mathrm{Xe}$ ), magic nuclei have been displayed a definite image (Figures 2a-b). And, it is undeniable that all magic nuclei together with their neighbor nuclei able to grow is so smooth in Table 1, which will be helpful to account for magic number phenomena in the future.

On the other hand, a nucleus might emerge different structures in ground and excited states. For example, a ${ }^{16} \mathrm{O}$ in ground state is ${ }^{16} \mathrm{O}_{\mathrm{c}-2+2}{ }^{4242}$ and in excited state is $4 \alpha$-structure that skin $2 \mathrm{~d}$ of ${ }^{16} \mathrm{O}_{\mathrm{c}-2+2}{ }^{4242}$ were combined $1 \alpha$; otherwise in ground state a $4 \alpha$-structure of ${ }^{16} \mathrm{O}$ is inconceivable to carry two hydrogen atoms to build a water molecule. Whereas a ${ }^{1} \mathrm{H}_{2}{ }^{16} \mathrm{O}$ will have in the main understood at a glance in Figure $2 \mathrm{~b}$. Also, it appears straightforward, if alternating single and double bonds of a benzene ring $\left({ }^{12,13,14} \mathrm{C}_{6}{ }^{1} \mathrm{H}_{6}\right)$, a buckyball $\left({ }^{12,13,14} \mathrm{C}_{60}\right)$, and diamond $\left({ }^{12,13,14} \mathrm{C}_{\mathrm{n}}\right)$ were rooted in a tetrahedral nucleus of ${ }^{12,13,14} \mathrm{C}$. Obviously, this covered atomic scope that was broadened to proton distribution, which presents another way to explain $Z$ that was shown to occupy constant spatial positions not only in nuclei, but in molecules (Figure 2b).

In conclusions, the compelling evidences suggest that a special shape of the periodic table is rooting in atomic nuclei that can only grow $1 \alpha$-particle in the $1^{\text {st }}$ layer intensified by $4 \mathrm{p}_{1}$ of ${ }_{27} \mathrm{Co},{ }_{28} \mathrm{Ni},{ }_{4} \mathrm{Rh}$, and ${ }_{46} \mathrm{Pd}$, and then grow $2^{3}, 2^{4}$, and $2^{5} \alpha$-particles together with nearly same number valence neutrons in the 2-3, 4-5, and 6-7 layers, respectively, that noble nuclei demonstrated perfect nucleon distributions, which is well consistent with the line of beta stability. Furthermore, the number of the elements $\left[2\left(2^{3}+2^{4}+2^{5}\right)\right.$ besides groups $\left.9-10 \mathrm{~B}\right]$ and valence neutrons $\left(2^{3}+2^{4}+2^{5}\right)$ in the 2-3, 4-5, and 6-7 steps being a square relation therefore indicates that a nucleus unusually is a two-dimensional structure in a nuclear phase, a folding nucleon disc that may be the heavier, the flatter, a possible reason resulting in super heavy element lives becoming shorter and shorter. Also, so that gives rise to it, a crude nucleon aspect was seemingly suggested from macrocosm. However, though here is an empirical nucleon distribution that could avoid stuck on details to some extent, it provides a visible nuclear image for the first time, which will benefit to further clarify and/or integrate nuclear, atomic, and molecular structures. It is significant, especially, in the present nanoparticle time. 


\section{Acknowledgments}

This work was partly supported by Changzhou bureau of science and technology, China. The author thanks Mr. Benlin Liu for a suggestion.

\section{References}

Amiel, S. (1969). Delayed neutrons in fission. In Proceedings of the Second IAEA Symposium on the Physics and Chemistry of Fission held by the International Atomic Energy Agency in Vienna (Vol. 28, pp. 569-590).

Bemis Jr, C. E., Ferguson, R. L., Plasil, F., Silva, R. J., Pleasonton, F., \& Hahn, R. L. (1977). Fragment-mass and kinetic-energy distributions from the spontaneous fission of No 252. Physical Review C, 15(2), 705.

Bohr, N. (1913). On the constitution of atoms and molecules. Phil. Mag., 26, 476-502.

Bohr, N., \& Wheeler, J. A. (1939). The mechanism of nuclear fission. Phys. Rev., 56, 426.

Bowman, H. R., Milton, J. C. D., Thompson, S. G., \& Swiatecki, W. J. (1963). Further studies of the prompt neutrons from the spontaneous of ${ }^{252} \mathrm{Cf}$. Phys. Rev., 129, 2133.

CERN. (2004). ISOLDE goes on the trail of superlatives. CERN Courier May 4.

Delaune, O. (2013). Isotopic yields distributions of transfer- and fution-induced fission from ${ }^{228} \mathrm{U}+{ }^{12} \mathrm{C}$ reactions in inverse kinematics. Phys. Rev. C, 88, 024605.

Fluss, M. J., Kaufman, S. B., Steinberg, E. P., \& Wilkins, B. D. (1973). Angular distribution of alpha particles in the spontaneous fission of ${ }^{252} \mathrm{Cf}$. Phys. Rev. C, 7, 353.

Flynn, K. F., Gindler, J. E., \& Glendenin, L. E. (1975). Distribution of mass in thermal-neutron-induced fission of ${ }^{257}$ Fm. Phys. Rev. C, 12, 1478.

Gindler, J. E., Flynn, K. F., Glendenin, L. E., \& Sjoblom, R. K. (1977). Distribution of mass, kinetic energy and neutron yield in the spontaneous of ${ }^{254} \mathrm{Fm}$. Phys. Rev. C, 16, 1483.

Hafstod, L. R., \& Teller, E. (1938). The alpha-particle model of the nucleus. Phys. Rev., 54, 681.

Hahn, O. (1921). Über ein neues radioaktives Zerfallsprodukt im Uran. Naturwissenschaften, 9(5), 84-84.

Haxel, O., Jensen, J. H. K. \& Suess, H. E. (1949). On the "magic numbers" in nuclear structure. Phys. Rev., 75, 1766.

Iyer, R. H., \& Cobble, J. W. (1966). Evidence of ternary fission at lower energies. Phys. Rev. Lett., 17, 541-545.

Jones, S. E., Palmer, E. P., Czirr, J. B., Decker, D. L., Jensen, G. L., Thorne, J. M., .. \& Rafelski, J. (1989). Observation of cold nuclear fusion in condensed matter. Nature, 338(6218), 737-740.

Klingensmith, D. L., \& Porile, N. T. (1988). Fragment emission in the interaction of ${ }^{238} \mathrm{U}$ with $400 \mathrm{Gev}$ protons. Phys. Rev. C, 38, 818.

Konecny, E., Specht, H. J., \& Weber, J. (1973). Symmetric and asymmetric fission of Ra- and Ac-isotopes. Proc. IAEA Symp. Phys. Chem. Fission, 2, 3-18.

Lewis, G. N. (1916). The atom and the molecule. J. Am. Chem. Soc., 38, 762.

Moseley, H. G. J. (1913). The high frequency spectra of the elements. Phil. Mag., 26, 1024.

Muga, M. L., Rice, C. R., \& Sedlacek, W. A. (1967). Ternary fission of heavy nuclei. Physical Review Letters, 18(11), 404-408.

Piasecki, E., \& Nowicki, L. (1979). Polar emission in fission. In Physics and chemistry of fission (pp. 193-221).

Piasecki, E., Dakowski, M., Krogulski, T., Tys, J., \& Chwaszczewska, J. (1970). Evidence of the polar emission of alpha-particles in the thermal neutron fission of 235U. Physics Letters B, 33(8), 568-570.

Poenaru, D. N., Ivascu, M., \& Sandulescu, A. (1979). Alpha-decay as a fission-like process. J. Phys. G: Nucl. Phys., 5(10), L169-L173.

Rose, H. J., \& Jones, G. A. (1984). A new kind of natural radioactivity. Nature, 307, 245.

Schmitt, H. W., Neiler, J. H., Walter, F. J., \& Chetham-Strode, A. (1962). Mass distribution and kinetics of ${ }^{235} \mathrm{U}$ thermal-neutron-induced three-particle fission. Phys. Rev. Lett., 9, 427.

Thomas, T. D., \& Vandenbosch, R. (1964) Correlation of fission-fragment kinetic-energy fine structure with a semiempirical surface. Phys. Rev., 133, B976.

U.S. National Nuclear Data Center. (n.d.). Nudat 2. 
Unik, J. P., Gindler, J. E., Glendenin, L. E., Flynn, K. F., Gorski, A., \& Sjoblom, R. K. (1974). Fragment mass and kinetic energy distributions for fissioning systems ranging from mass 230 to 256. In Physics and chemistry of fission (pp. 19-46).

Wild, J. F., Baisden, P. A., Dougan, R. J., Hulet, E. K., Lougheed, R. W., \& Landrum, J. H. (1985). Light-chargedparticle emission in the spontaneous fission of ${ }^{250} \mathrm{Cf},{ }^{256} \mathrm{Fm}$ and ${ }^{257} \mathrm{Fm}$. Phys. Rev. C, 32, 488.

\section{Copyrights}

Copyright for this article is retained by the author(s), with first publication rights granted to the journal.

This is an open-access article distributed under the terms and conditions of the Creative Commons Attribution license (http://creativecommons.org/licenses/by/4.0/). 